Case Report

\title{
A Rare Mullerian Duct Anomaly Not Included in the Classification System by the American Society for Reproductive Medicine
}

\author{
Shereene J. Brown and Shawky Z. A. Badawy \\ Department of Obstetrics and Gynecology, State University of New York Upstate Medical University, 736 Irving Avenue, Syracuse, \\ NY 13210, USA \\ Correspondence should be addressed to Shawky Z. A. Badawy; badawys@upstate.edu
}

Received 31 January 2013; Accepted 27 February 2013

Academic Editors: J. Awwad, P. De Franciscis, C. Ficicioglu, and D. Hellberg

Copyright (c) 2013 S. J. Brown and S. Z. A. Badawy. This is an open access article distributed under the Creative Commons Attribution License, which permits unrestricted use, distribution, and reproduction in any medium, provided the original work is properly cited.

This is a case report of a 37-year-old female with a uterine septum (two cavities), a normal single fundal contour, two cervices, and a longitudinal vaginal septum. This is a rare finding that is not described in the current classification system by the American Society for Reproductive Medicine.

\section{Introduction}

Mullerian duct anomalies have become more easily diagnosed due to better imaging modalities over the last few decades. The incidence has been quoted as low as $0.001 \%$ and as high as $10 \%[1]$. It is theorized that the mullerian ducts fuse around the eleventh through the thirteenth weeks in utero and that fusion and absorption are unidirectional from caudal to cephalad [1-3]. Our current classification system for uterine anomalies is based on this unidirectional theory [4]. The majority of uterine anomalies can be explained by this theory; however, there are a number of cases that do not fit this paradigm [4]. The case described here is a mullerian duct anomaly with a longitudinal vaginal septum, two cervices, a uterine septum, and a single normal fundus. This represents failure of absorption of the septum that separates the mullerian ducts after fusion.

\section{A Case Report}

37-year-old G1P0101 was referred to the Reproductive Endocrinology Division because of chronic dyspareunia and secondary infertility. She had a prior Caesarean delivery where it was discovered that she had an unspecified mullerian duct anomaly. She now had a new partner and had been trying to get pregnant for three years. She had regular cycles with normal flow. On physical examination, a vaginal septum and two cervices were observed.

She had an MRI that showed a smooth single external uterine fundal contour without a cleft (Figure 1). There were two separate endometrial channels (Figure 2) and two upper cervical canals (Figure 3). This was thought to be consistent with a septate uterus, possible bicornuate bicollis, but not indicative of didelphys uterus. The lack of a notch between the two uterine canals suggested uterine pseudodidelphys. Another possibility was a complete septate uterus with double cervices and double vaginas. Of note, there were no renal anomalies on ultrasound.

The patient underwent examination under anesthesia, excision of the vaginal septum, and hysterosalpingogram (HSG). The uterine cavities were sounded. The left uterine cavity sounded to 3.5 inches, and the right uterine cavity sounded to 2 inches. Both uterine cavities were cannulated at the same time, and there was a septum. During the HSG, the left cervix and uterus spilled Omnipaque dye through the left fallopian tube, and, likewise, the right cervix and uterus spilled dye through the right fallopian tube. A laparoscopy was also performed demonstrating one uterine fundus, two fallopian tubes, and two ovaries. The decision was made not to remove the uterine septum because both uterine cavities 


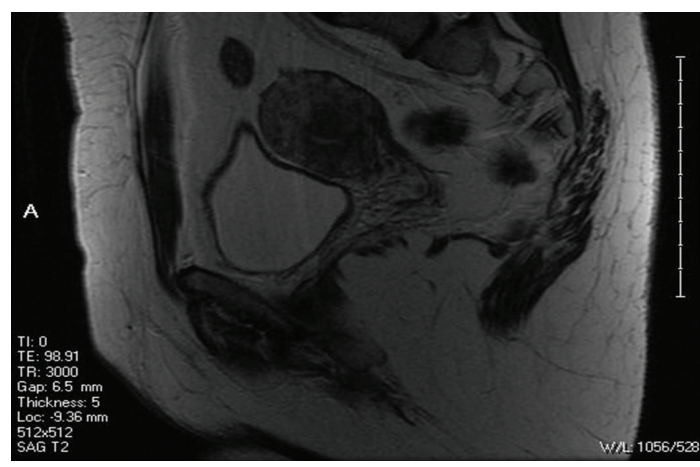

FIGURE 1: Sagittal view; note the smooth contour of the uterus.

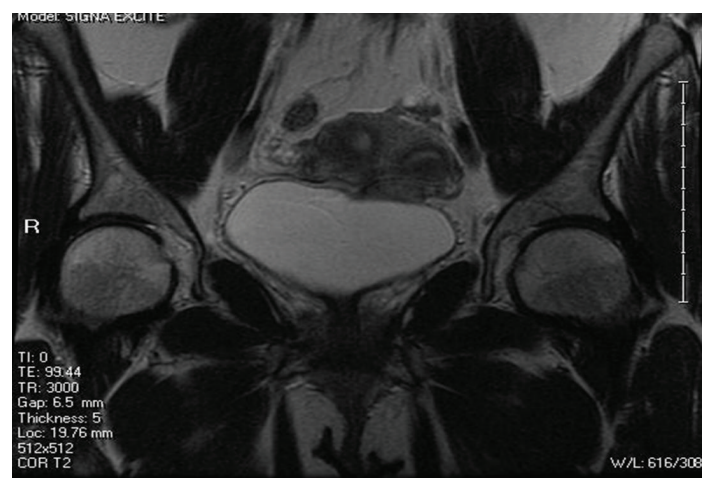

FIGURE 2: Coronal view; note the two uterine cavities, myometrium, and thick septum.

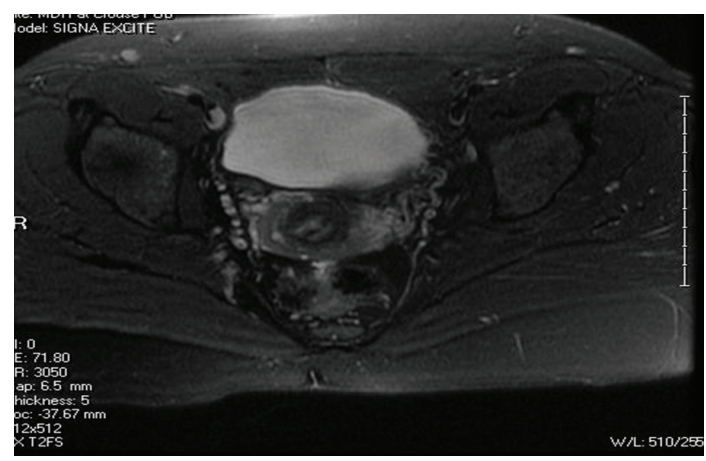

Figure 3: Axial view; note the cervices and two canals.

were functional and she could achieve pregnancy in either cavity. Her dyspareunia improved following the removal of the vaginal septum.

On semen analysis, her husband was found to have azoospermia secondary to chemotherapy and radiation therapy. As a result of this revelation, the patient decided to proceed with artificial insemination with donor sperm.

\section{Discussion}

The etiology of mullerian duct anomalies is not well understood $[4,5]$. Most defects are polygenic and multifactorial [5]. The classification system for uterine anomalies by the
American Society for Reproductive Medicine (ASRM) is based on six groups $[4,6]$. Greater than $90 \%$ of mullerian duct anomalies can be grouped in the ASRM classification system [5]. Of the mullerian duct anomalies, the most common is the septate uterus [5]. This case represents a uterine anomaly that is not part of the ASRM classification system.

Similar to the aforementioned case, there are cases in the literature that describe normal uteri with double cervices. Pavone et al. described a case with a septate uterus, two cervices, and a smooth fundus [1]. Shirota et al. described a case with a normal uterus, a double cervix that communicated at the internal os, and a vagina with a longitudinal septum [2]. Dunn and Hantes described a case where hysteroscopy revealed one normal cervix and the other cervix ended in a blind pouch [4]. Duffy et al. described a case with a longitudinal vaginal septum with two cervices and a normal fundus with two uterine cavities [7]. Chang et al. described five cases with uterine septum, double cervices, and vaginal septum [8]. Ribeiro et al. reported that, since 1994, approximately 40 cases of this particular anomaly have been reported [9].

The above cases are very similar in that they represent mullerian duct anomalies that do not fit into the ASRM classification system. We would like to propose the inclusion of this rare anomaly in an amended classification system by the American Society for Reproductive Medicine.

\section{References}

[1] M. E. Pavone, J. A. King, and N. Vlahos, "Septate uterus with cervical duplication and a longitudinal vaginal septum: a müllerian anomaly without a classification," Fertility and Sterility, vol. 85, no. 2, pp. 494.e9-494.e10, 2006.

[2] K. Shirota, M. Fukuoka, H. Tsujioka, Y. Inoue, and T. Kawarabayashi, "A normal uterus communicating with a double cervix and the vagina: a müllerian anomaly without any present classification," Fertility and Sterility, vol. 91, no. 3, pp. 935.e1935.e3, 2009.

[3] W. M. Crosby and E. C. Hill, "Embryology of the Mullerian duct syytem. Review of present-day theory," Obstetrics and Gynecology, vol. 20, pp. 507-515, 1962.

[4] R. Dunn and J. Hantes, "Double cervix and vagina with a normal uterus and blind cervical pouch: a rare müllerian anomaly," Fertility and Sterility, vol. 82, no. 2, pp. 458-459, 2004.

[5] R. N. Troiano and S. M. McCarthy, "Müllerian duct anomalies: imaging and clinical issues," Radiology, vol. 233, no. 1, pp. 19-34, 2004.

[6] V. C. Buttram, V. Gomel, A. Siegler, A. DeCherney, W. Gibbons, and C. March, "The American Fertility Society classifications of adnexal adhesions, distal tubal occlusion, tubal occlusion secondary to tubal ligation, tubal pregnancies, Mullerian anomalies and intrauterine adhesions," Fertility and Sterility, vol. 49, no. 6, pp. 944-955, 1988.

[7] D. A. Duffy, J. Nulsen, D. Maier, D. Schmidt, and C. Benadiva, "Septate uterus with cervical duplication: a full-term delivery after resection of a vaginal septum," Fertility and Sterility, vol. 81, no. 4, pp. 1125-1126, 2004.

[8] A. S. Chang, C. L. Siegel, K. H. Moley, V. S. Ratts, and R. R. Odem, "Septate uterus with cervical duplication and longitudinal vaginal septum: a report of five new cases," Fertility and Sterility, vol. 81, no. 4, pp. 1133-1136, 2004. 
[9] S. C. Ribeiro, L. Y. S. Yamakami, R. A. Tormena, W. S. Pinheiro, J. A. M. de Almeida, and E. C. Baracat, "Septate uterus with cervical duplication and longitudinal vaginal septum," Revista da Associacao Medica Brasileira, vol. 56, no. 2, pp. 254-256, 2010. 


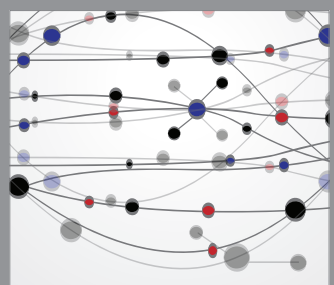

The Scientific World Journal
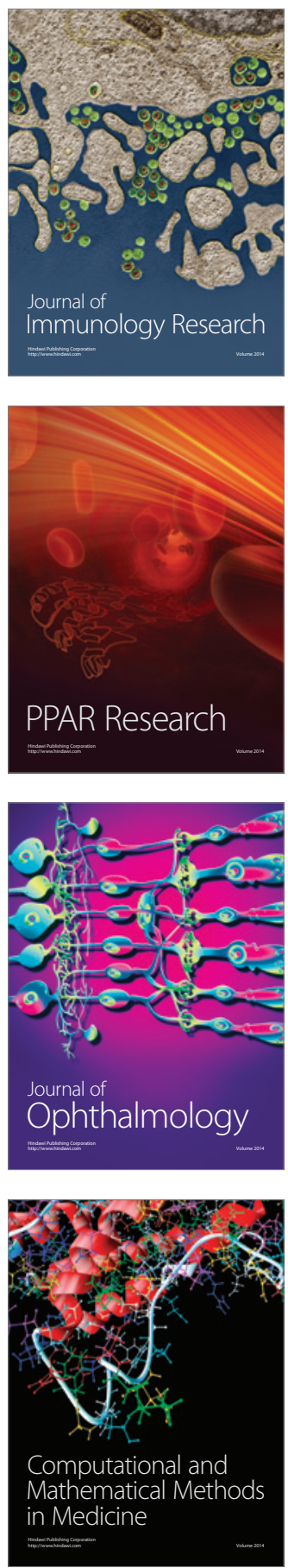

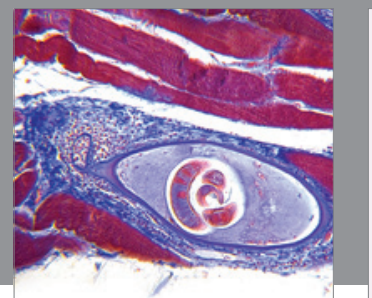

Gastroenterology

Research and Practice
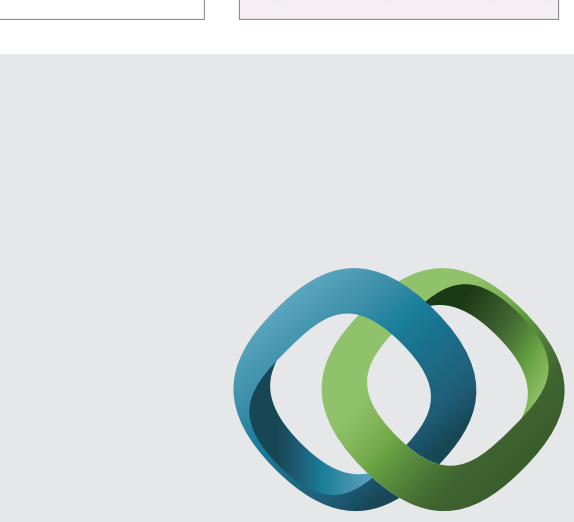

\section{Hindawi}

Submit your manuscripts at

http://www.hindawi.com
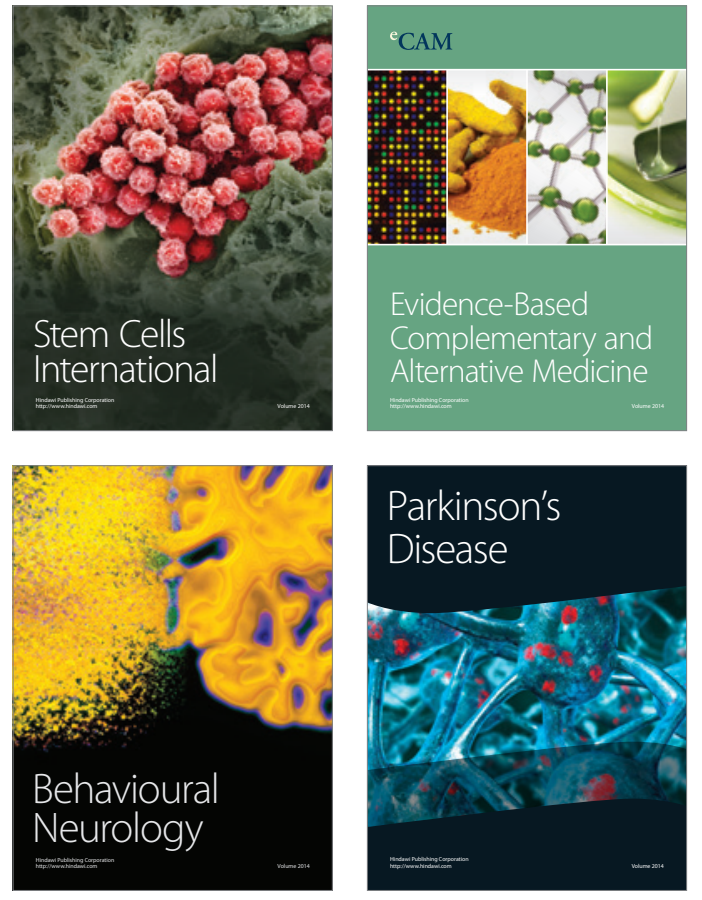
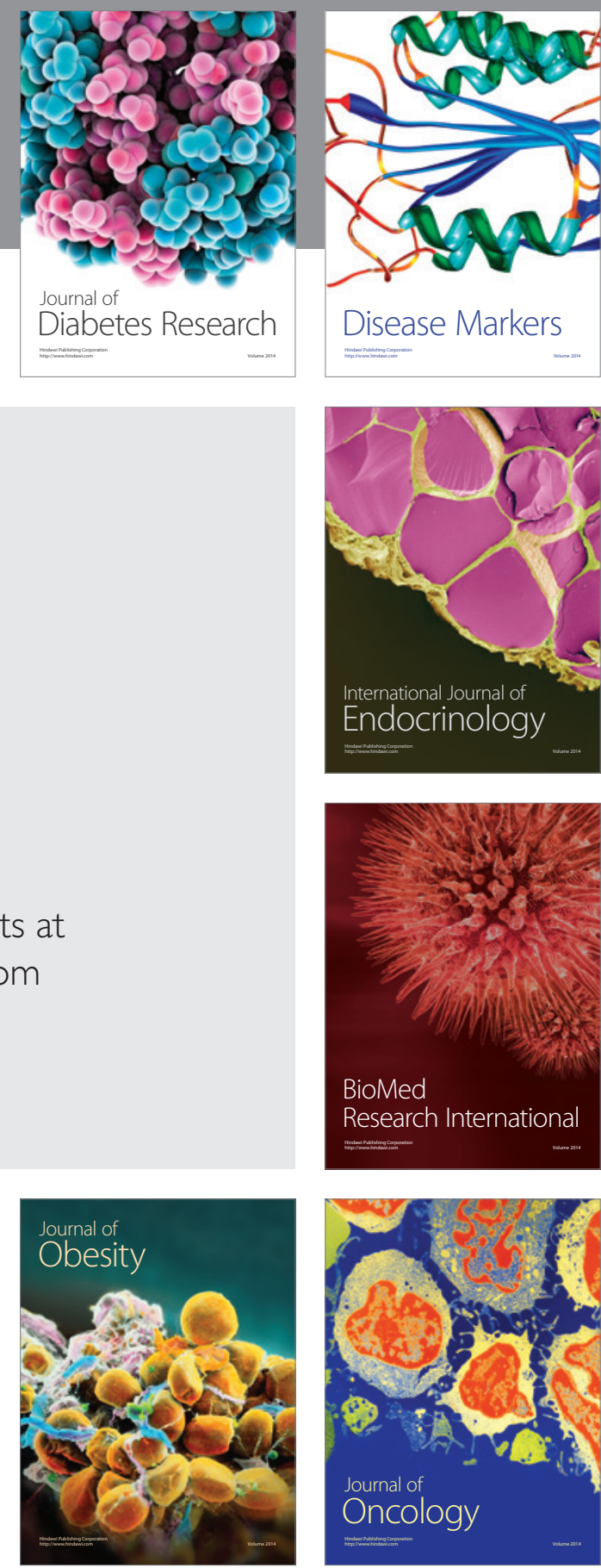

Disease Markers
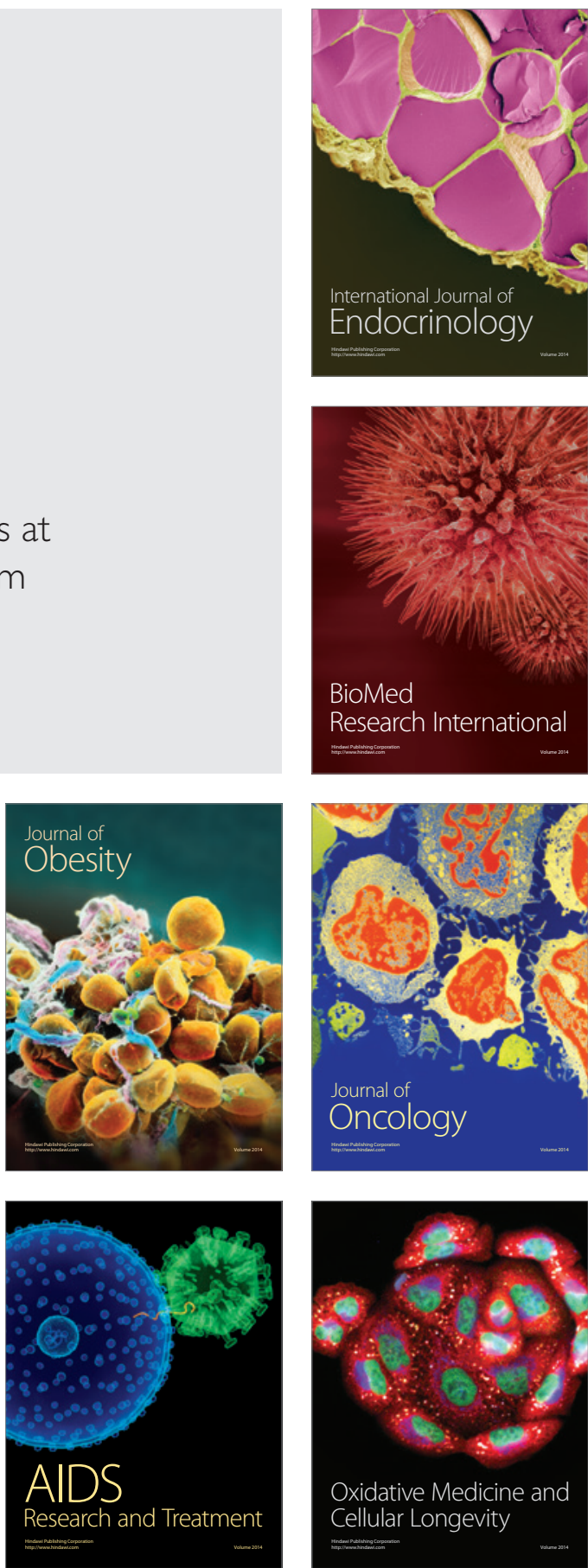